\title{
High-speed Railways and Environmental Pollution: The Mediating Effect of Environmental Regulations and Moderating Effect of Officials' Political Promotion Incentives
}

\author{
Liping Li ( 751133624@qq.com ) \\ Chengdu University \\ Yuandi Wang \\ Sichuan University - Wangjiang Campus: Sichuan University \\ Qisheng Chen \\ Sichuan University - Wangjiang Campus: Sichuan University \\ Jiang Wu
}

Southwestern University of Finance and Economics School of Statistics

Ximeng Jia

Sichuan University - Wangjiang Campus: Sichuan University

\section{Research Article}

Keywords: high-speed railways, environmental pollution, environmental regulations, political promotion incentives

Posted Date: November 1st, 2021

DOI: https://doi.org/10.21203/rs.3.rs-946787/v1

License: (c) (i) This work is licensed under a Creative Commons Attribution 4.0 International License.

Read Full License 


\section{High-speed Railways and Environmental Pollution: The}

2 Mediating Effect of Environmental Regulations and Moderating

3 Effect of Officials' Political Promotion Incentives

${ }^{1}$ Business School of Chengdu University, Chengdu, 610106, Sichuan, China;

2 Business School of Sichuan University, Chengdu, 610064, Sichuan, China;

${ }^{3}$ School of Statistics, Southwestern University of Finance and Economics, Chengdu 611130, Sichuan, China

* Corresponding authors. E-mail addresses: jxm1313@126.com;

Abstract: This study examines the relationship between high-speed railways (HSRs) and environmental pollution by focusing on the mediating role of environmental regulations and the moderating role of officials' political promotion incentives. Based on a sample of 113 prefecture-level cities, with balanced panel data in China from 2009 to 2017, using the difference-in-differences (DID) model, the results show that HSRs can reduce environmental pollution via the mediating effect of environmental regulations. Additionally, high officials' political promotion incentives can strengthen this mediating effect. A propensity score matching with difference-in-differences (PSM-DID) model is used to solve endogenous problems, and a placebo test and a parallel trend test indicate that these results are robust. This study encourages the government to rationally promote the construction of high-speed railways and expand the social advantages of high-speed railways to improve environmental regulations and reduce environmental pollution. Keywords: high-speed railways, environmental pollution, environmental regulations, political promotion incentives number:72002144)

Conflicts of Interest: The authors declare no conflicts of interest. supported the data collection. Jiang $\mathrm{Wu}$ examined the manuscript and give advice on manuscript submission. Ximeng Jia revised the manuscript. 
The rapid economic growth over the past three decades has led to severe environmental problems in developing countries (Mayer, 1999). Various studies have determined that environmental regulations can control environmental pollution (He and Zhang, 2021). Environmental regulators include the government, investors, and community monitors (Millimet and Roy, 2016). According to reputation theory, firms regard reputation as a precious resource for competition in the market. Negative environmental news can reduce stock prices and induce losses in market value (Hitzhusen, 2000). To maintain a good reputation, firms have to obey the law and rules of environmental protection and respond positively to the monitor from the investors and community (J. W. Shen, Yehua Dennis Yang, Zi 2017).

However, asymmetric information exists between firms and regulators, which increases the cost and reduces the efficiency of environmental regulations (Jebjerg and Lando, 1997). For instance, Grossman argues that information asymmetry exists between investors and firms. Owing to the lack of reliable information, investors tend to expect the worst, driving down share prices without adequate disclosure by managers (S. J. Grossman, 1981). Thus, increasing transparency and comprehensive information disclosure are crucial for reducing the degree of information asymmetry and promoting the development and implementation of environmental regulations (Huang and Chen, 2015).

To control and reduce pollution emissions, many developing countries not only promulgated many policies to strengthen environmental regulations but also coordinated industrial upgrading and energy restructuring to curb pollution at its source. During this process, advanced environmentally friendly technology plays a very important role in pollution control. High-speed railways (HSRs) are environmentally friendly, can consume energy more efficiently, and reduce greenhouse gas emissions more significantly than other modes of transportation (D'Alfonso et al., 2016). Some studies have indicated that HSRs can directly reduce environmental pollution by providing an environmentally friendly technology advantage (S. Wang et al., 2020). In addition to the advantages of environmentally-friendly technology, some studies have demonstrated that HSRs can significantly reduce distances and travel times between cities (Kobayashi and Okumura, 1997). Further, they can speed up the flow of people, the spillover of information, knowledge, and technologies (Glaeser and Mare, 2001). With the introduction of high-speed railways, people are more likely to discover social problems, especially negative events, and spread this information more rapidly (DiMicco et al., 2007). Thus, we wonder whether this social advantage of HSRs, increasing transparency and comprehensive 
information disclosure, and reducing the degree of information asymmetry could have a positive effect on environmental regulations.

Furthermore, green development strategies are becoming important and urgent in developing countries (Halkos and Paizanos, 2013). The government in many developing countries have added environmental performance to the working criteria of officials. For example, the Chinese central government introduces "tournament competition" among officials by promoting or demoting them based on their comprehensive consideration of environmental performances and economic development (Bo, 1996). Officials who have strong political promotion incentives will be more sensitive to negative environmental events according to promotion tournament theory (DeVaro, 2006). To prevent the occurrence of negative environmental events, these officials are committed to strengthening environmental regulations and strictly monitoring firms' environmental pollution behavior in their jurisdiction.

The notion that the introduction of HSRs could directly reduce the environmental pollution has been verified in numerous papers ((Fan et al., 2020). However, the indirect effect of the introduction of HSRs on environmental pollution and its mechanism has not been thoroughly explored. To fill this gap, our study aims to explore the mechanism of the indirect effect of the introduction of HSRs on environmental pollution from the perspective of environmental regulations and officials' political promotion incentives. China was selected as the research object for this study. The country is experiencing severe levels of air pollution while still pursuing economic benefits. Thus, reducing air pollution is an urgent task for the Chinese government. Moreover, China is a successful example of developing large-scale HSR networks with advanced technology. By the end of 2017, the length of inter-city HSRs in operation in China was more than $25000 \mathrm{~km}$, and $66.3 \%$ of the total mileage globally, ranking first in the world. ${ }^{1}$

Our research employed prefecture-level panel data for 113 Chinese cities that have pollution information transparency index reports (Tu et al., 2019) from 2009 to 2017 for an empirical analysis. Specifically, in accordance with information asymmetry theory (Quanqi Liu and Li Li, 2019), we examine the effect of the introduction of HSRs on environmental regulations. According to reputation theory (Gioia et al., 2000), environmental regulations are considered a mediating factor in the relationship between HSRs and environmental pollution. Moreover, according to the promotion tournament theory, the moderated mediation effect of officials' political promotion incentives on the indirect relationship between the introduction of HSR

\footnotetext{
http://www.chinanews.com/
} 
and environmental pollution controlled through environmental regulations was tested (DeVaro, 2006).

The contribution of this study to the literature is threefold. First, previous research has emphasized the direct effect of HSRs only. We propose a new conceptual framework for the indirect influence of HSRs on environmental pollution with respect to environmental regulations, which enriches the literature on path analyses of the impact of HSRs on environmental pollution. Second, many studies have focused on the relationship between environmental regulations and pollution (J. Shen et al., 2017). This study attempts to expand the relationship between environmental pollution and environmental regulations by inserting HSRs, which connects the HSRs research with the environmental regulations' literature. Third, this study builds an indirect relationship between officials' political promotion incentives and environmental pollution, which extends their existing direct relationship (Zheng et al., 2014a). The existing literature points out that political promotion incentives can positively and directly reduce environmental pollution (Kahn et al., 2015). Our research finds that political promotion incentives positively moderate the relationship between environmental regulations and environmental pollution.

This research has significant implications for policymakers in practice. First, our study indicates that the introduction of HSRs can indirectly reduce environmental pollution through their social advantage via the mediation effect of environmental regulations, which provides policymakers with a new perspective to curb environmental pollution. Governments should not only make efficient use of the technological advantages of HSRs, but also attach importance to their social advantages. Promoting the influence of HSRs on environmental regulations is an effective way to control environmental pollution. Second, our paper exposes officials' strong political incentives that can prompt environmental regulations and further positively control pollution. Governments could develop a suitable officials' political promotion mechanism by considering environmental pollution control performance assessment.

The remainder of this paper is organized as follows. In Section 2, we review the relevant literature and introduce five hypotheses. Then, we introduce the data, variables, and research methods in Section 3. In Section 4, we discuss the empirical results. Finally, in Section 5, the principal findings are summarized, and theoretical and practical implications are presented. This section also discusses the limitations of this study in guiding future research.

\section{Theoretical framework and research hypothesis}

\subsection{HSRs and environmental pollution}


114 The effect of HSRs on environmental pollution can be analyzed from the perspective of direct and indirect

115 impacts. Regarding the direct impact, HSRs are encouraged because of their low carbon and high efficiency 116 advantages. Givoni (2007) found that, comparing the emissions, impact, and damage costs of air travel and 117 high-speed rail travel, it is beneficial to replace airplane seats with high-speed rail seats. Janic (2011) stated that this substitution effect involves reducing the amount and associated costs of social and environmental impacts, such as airport airside delays, noise, and local and global emissions of greenhouse gases. Considering the indirect impacts, the high-speed rail can reduce air pollution through an innovative effect, allocating effect, and substituting effect, which is discussed by Yang et al. (2019). HSRs can not only transport people and goods but also accelerate innovation, improve resource utilization efficiency, and substitute industrial structures, which can reduce pollution (Vickerman, 2018). Based on these results, we can develop hypothesis 1:

H1: The introduction of HSRs can reduce the environmental pollution.

\subsection{HSRs and environmental regulations}

There is asymmetric information between firms and regulators, which increases the difficulties and costs of environmental regulations. According to information asymmetry theory, a party with more information is in an advantageous position in terms of economic activity (Quanqi Liu and Li Li, 2019). Meanwhile, firms are in an advantageous position in terms of pollution information disclosure. To pursue maximum economic benefits, firms tend to sacrifice environmental protection. Nevertheless, according to reputation theory, they need to build a good public reputation for environmental protection to further economic development (Gioia et al., 2000). As a result, firms are motivated to deliberately withhold information on pollution. This asymmetric information will increase the difficulty for regulators to discover the truth and obtain comprehensive information. Furthermore, regulators may make unsound environmental regulations decisions that adversely affect pollution control. Therefore, reducing asymmetric information is the key point for environmental regulations.

Nowadays, the internet and videoconferencing have been greatly developed. However, for business,

138 individuals' awareness and participation in discussions will increase, more problems will be identified, and more information will be shared. As a result, negative information spreads more rapidly and frequently according to the negativity bias theory (Yan and Jiang, 2018). Some existing literature has indicated that the introduction of HSRs can reduce the time and geographical distance among different cities, promote face-toface communication, and enhance knowledge spreading between regions (Lin, 2017). HSRs not only carry 
people and goods but also "carry" information and act as information nodes. The introduction of HSRs provides

144 people more opportunities for discussion and communication. More information on firms' environmental 145 pollution will be discovered during face-to-face communication by the government and investors, which can reduce asymmetric information (DiMicco et al., 2007). In this situation, environmental regulations will be strengthened, and firms will be forced to reduce emissions (Gioia et al., 2000). Therefore, this discussion leads to the development of hypothesis 2 as follows:

H2: The introduction of HSRs can promote effective implementation of environmental regulations.

\subsection{Environmental regulations and environmental pollution}

Formal environmental and informal environmental regulations exert powerful effects on firms' active participation in environmental pollution ( $\mathrm{Li}$ et al., 2017). The government or political institutions are the primary formal regulators that monitor firms' emissions and enforcement of standards, while informal regulations depends on the supervision of investors, shareholders, and communities (Féres and Reynaud, 2012). According to reputation theory, reputation is a precious resource that can gain a competitive advantage for firms in comparison to similar distributors. To prevent negative judgment, investors and shareholders use environmental information in unsophisticated ways to pressure firms to voluntarily reduce their pollution. Additionally, community pressure has an indirect effect on firms’ pollution control (Kathuria, 2007).

Studies have indicated that environmental regulations positively influences environmental performance. Matthew A. Cole (2005) analyzed the UK manufacturing sector to explore industrial characteristics, environmental regulations, and air pollution, finding that both formal and informal regulations are successful in reducing pollution intensity. Qi et al. (2019) evaluated the effectiveness of environmental regulations in reducing pollution, improving efficiency, and revealing the systematic heterogeneity therein. Other papers have obtained results (Silajdzic and Mehic, 2017). Consequently, this discussion leads to the development of hypothesis 3 :

H3: Environmental regulations can reduce environmental pollution.

\subsection{Mediating role of environmental regulations}

Hypothesis 2 predicts that the introduction of HSRs can improve environmental regulations. With the introduction of HSRs, more information on firms' environmental pollution will be discovered by the government and investors, which can reduce asymmetric information and further promote the effective implementation of environmental regulations (Cohen and Santhakumar, 2007). Hypothesis 3 predicts the 
improved environmental regulations can reduce environmental pollution (H. Wang and Liu, 2019). Together, these hypotheses specify a model in which environmental regulations plays a mediating role in the relationship between the introduction of HSRs and environmental pollution. Therefore, we propose hypothesis 4:

H4: Environmental regulations mediate the relationship between the introduction of HSRs and environmental pollution.

\subsection{Moderated mediation role of officials' political promotion incentives}

In the past, GDP growth was the primary criterion used by upper-level governments to evaluate the performance of lower-level officials' performance and promotion (H. Zhang et al., 2018). Since the release of the "11th FiveYear Plan" in China, energy conservation and pollution reduction have been considered in performance evaluations and promotion criteria of local officials. This has been implemented to address the principal-agent problem in the pursuit of a sustainable development strategy (Zheng et al., 2014b).

In this situation, according to promotion tournament theory (DeVaro, 2006), local officials who have strong political promotion incentives will be more sensitive to pollution news in their jurisdictions. If severe pollution remains or accidents occur, local government leaders will become demoted or dismissed. Thus, to increase the chance of promotion, local government leaders who have strong political promotion incentives will reinforce government regulations on pollution reduction, pay more attention to public participation, and implement a response as soon as possible. Thus, we can predict that officials' political promotion incentives can moderate the relationship between environmental regulations and environmental pollution.

Environmental regulations mediate the relationship between the introduction of HSRs and environmental pollution. We can deduce that officials' political promotion incentives moderate the mediating effect of environmental regulations on the relationship between the introduction of HSRs and environmental pollution. From this, we can develop hypothesis 5:

H5: Officials' political promotion incentives moderate the mediating effect of environmental regulations on the relationship between the introduction of HSRs and environmental pollution, such that this relationship is strong in the presence of strong political promotion incentives.

Be with five above hypotheses, the conceptual model is illustrated in Figure 1. 


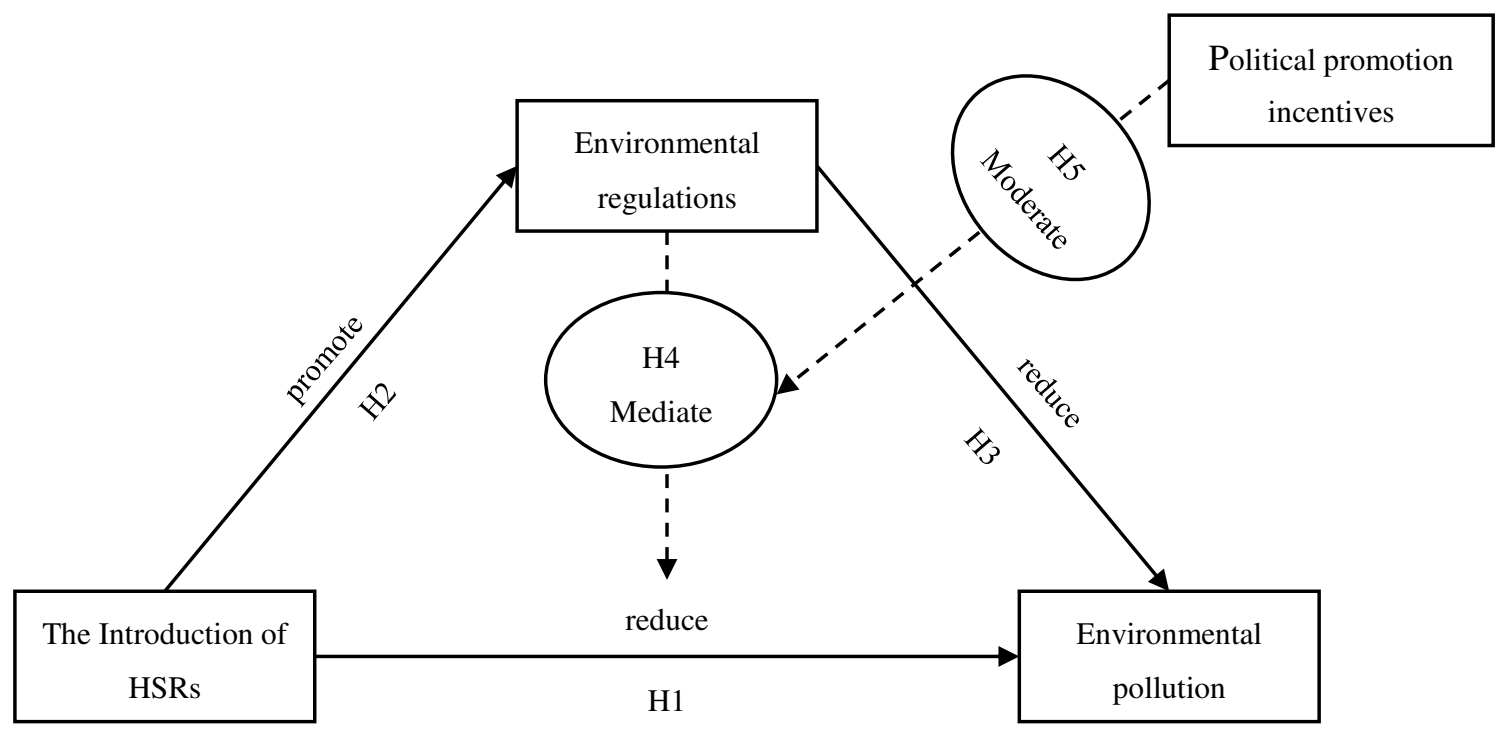

3. Methodology and data

\subsection{Data sources and variable selection}

\subsubsection{Data sources}

We obtain the HSR data by looking up the relevant information in the China Railway Yearbook and 12306.com.

The implementation of HSRs in each city was manually sorted and the distribution of China's HSR cities is shown in Figure 2. The first HSR line was introduced in 2008. HSRs were introduced every year from 2009 to the present. By 2017, there were 213 prefecture-level cities and municipalities with HSRs. Because several HSR lines in China were introduced at the end of the year, and the impact of HSRs may not be apparent in such a short period, the introduction year of HSR is delayed by one year in our model.

The original resource of environmental pollution data used in this study is from the Chinese Cities Statistical Yearbook. We supplement the missing data by using the average growth rate of each city. The environmental regulations data are from the Pollution Information Transparency Index reports, which were jointly published by the Institute of Public and Environmental Affairs (IPE) and the Natural Resources Defense Council (NRDC) (Tu et al., 2019). In these reports, the governance, and regulations indexes of 113 cities were disclosed (extended to 120 cities in 2013), and they have been published since 2008. These 113 cities are facing severe environmental pollution but play an important role in economic development, making them prominent targets for environmental protection regulations. 

provincial yearbooks, and www.xinhuanet.com. In China, two leaders exist simultaneously in a city, the mayor, and the Chinese Communist Party secretary. According to the law, the mayor is the executive officer of the municipal government in charge of daily governmental operations, such as economic growth, energy conservation, and environmental protection (Tu et al., 2019). Thus, we primarily discuss political incentives for the mayor.

Considering the delayed observation window, we chose the 113 cities that have Pollution Information

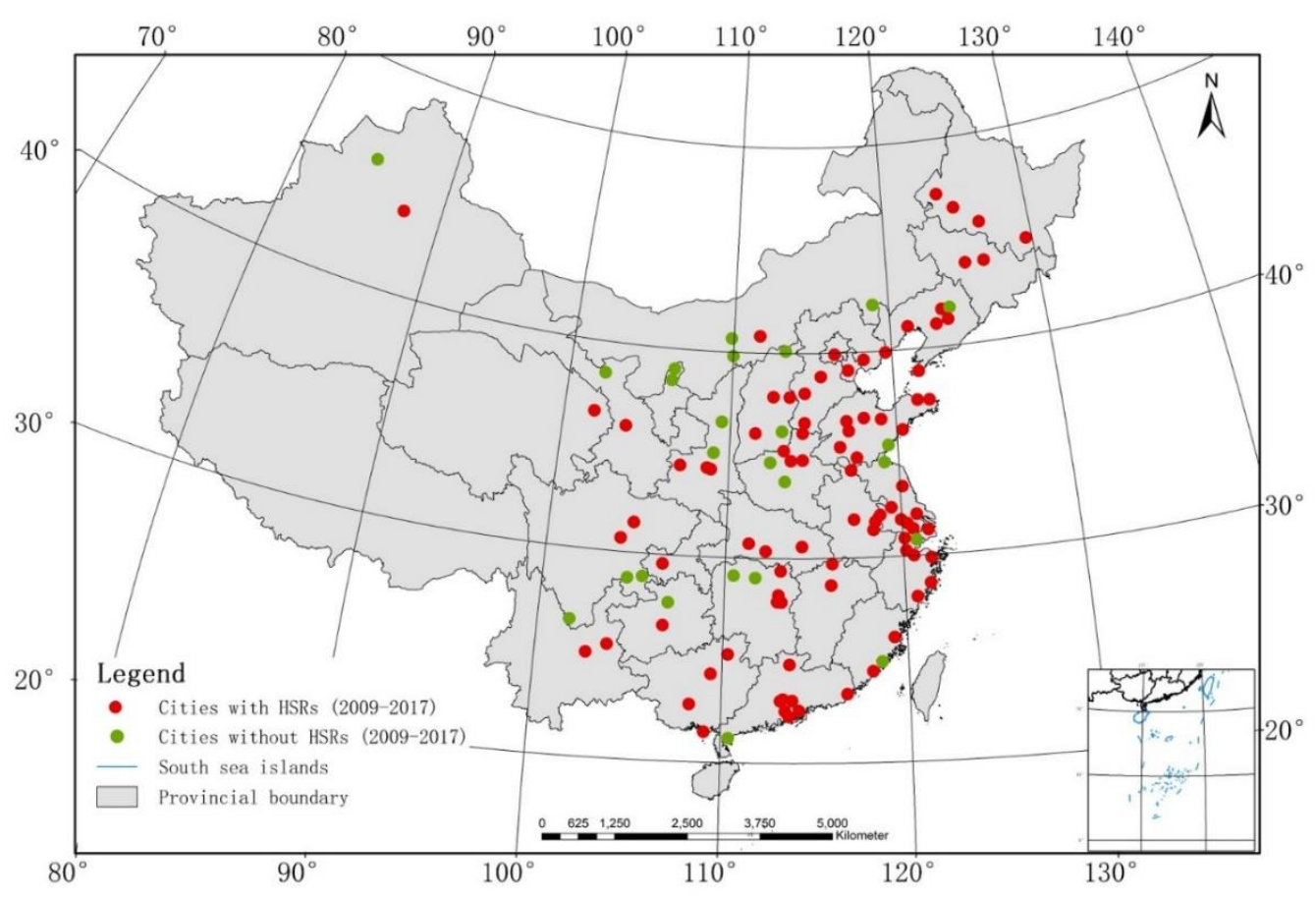

Figure 2 Distribution map of cities with Pollution Information Transparency Indexes

\subsubsection{Dependent variable}

The pollution in Chinese cities comes from industrial pollution sources and includes air and water pollution (Chen et al., 2012). Air pollution is primarily caused by industrial $\mathrm{SO}_{2}$, industrial NOx, and soot, whereas water pollution is generally created by wastewater from plants (Rohde and Muller, 2015). In our research, we selected industrial $\mathrm{SO}_{2}$ emissions, industrial $\mathrm{NO}_{\mathrm{x}}$ emissions, soot emissions, and industrial wastewater emissions as environmental pollution indicators. For simplicity and convenience, we integrated the above indicators using a principal composition analysis method and created an aggregative pollution index called pollution. 
245 We set $H S R$ as the independent variable in our empirical analysis and operationalized it as a dummy variable.

246 Because we use the difference-in-differences (DID) method for our empirical analysis, we construct a group 247 dummy variable, $d z$, and a time dummy variable, $d t$. The interaction term $d z * d t$ is our focus, which is described 248 as the "policy treatment effect" of an HSR, and we define it as $H S R \equiv d z^{*} d t$. Regarding $d z$, we set cities with HSR services from 2009 to 2017 as the treated group and let $d z=1$. We set cities that do not have HSR services from 2009 to 2017 as the untreated group and let $d z=0$. For $d t$, if the observation year is before the year of an HSR introduced, we set $d t=0$; otherwise, $d t=1$. Thus, $H S R=1$ when $d z=1$ and $d t=1$; otherwise, $H S R=0$.

\subsubsection{Control variables}

Population density (Popu_density): Environmental pollution can be affected by population density, which is calculated as the population divided by the area. A high population density will create more environmental pollution (Hixson et al., 2012). Whether or not to open an HSR in cities is related to its population density.

Industrial structure (Second industry): Environmental pollution and the introduction of HSR will be affected by industrial structure. Environmental pollution is primarily emitted by secondary industries (Managi and Kaneko, 2009). We consider the proportion of secondary industries a part of GDP to reflect the impact of the industrial structure on environmental pollution.

Ratio of foreign direct investment to GDP (FDI): The ratio of foreign direct investment to GDP will be heterogeneous for different cities in terms of pollution emissions. Foreign direct investment can increase emissions and may induce a pollution haven effect (Tang, 2015). This study uses the proportion of foreign direct investment in GDP to reflect the effects of foreign direct investment on environmental pollution emissions.

Number of Internet users (Net): Public environmental regulations require information transfer and spread. As a good information transfer carrier, the Internet plays an important role in promoting environmental regulations. Thus, we use the number of internet users to reflect information transfer.

Economic development (Per capita GDP): According to the Environmental Kuznets Curve theory proposed by G. M. Grossman and Krueger (1995), there is an inverted U-curve relationship between economic growth and environmental pollution. Therefore, this paper uses the square term of logarithm GDP per capita to calculate economic development. 
We used the pollution information transparency index (PITI) as our mediating variable to calculate the environmental regulations of a city. The pollution information transparency index (PITI) is a score assessed by the Institute of Public and Environmental Affairs (IPE) and the Natural Resources Defense Council (NRDC) based on the eight indicators ${ }^{2}$ in implementing the open environmental information measures ${ }^{3}$ (Tu et al., 2019).

276 PITI aims to evaluate the transparency level of environmental information disclosure and pollution regulatory information disclosure in 113 cities (this increased to 120 after 2013) (Li et al., 2017). Higher PITI scores represent a higher level of pollution supervisory information disclosure and a higher level of public participation (L. Zhang et al., 2016). PITI information disclosure can effectively help the public to supervise and measure the degree of environmental pollution. Further, with the help of environmental information transparency, local governments have strengthened environmental regulations. Thus, the PITI could serve as a proxy variable for evaluating environmental regulations.

\subsubsection{Moderator variable}

We set officials' political promotion incentives (Pro_incent) as a moderator variable, which was measured by a proxy variable. A mayor's age reflects the political promotion incentives. The Chinese Communist Party has emphasized the appointment and promotion of younger cadres while restricting the promotion of aging officials ${ }^{4}$. According to the Interim Provisions for Party and Government Leading Cadre Tenure, mayors below the age of 57 can be promoted to higher-level positions (Kou and Tsai, 2014). Zhou and Zeng (2018) also found that mayors who were below the age of 57 had stronger promotion incentives. If they cannot get promoted before this age, they are less likely to be promoted afterward and retire with relatively lower pension packages. Based

291 on this analysis, we choose a mayor's age as a proxy variable to represent his or her political promotion 292 incentives and define it as a dummy variable. If a mayor's age is less than 57, we regard this mayor as having 293 strong political promotion incentives, and Pro_incent equals 1; otherwise, Pro_incent equals 0.

294 The variables, brief descriptions of the variables, and basic descriptive statistics are shown in Table 1.

Table 1 Variables and brief descriptions of the variables

\footnotetext{
${ }^{2}$ The eight indicators include disclosures of: enterprise violations, results of EPB enforcement campaigns, clean production audit information, enterprise environmental performance ratings, disposition of petitions and complaints, environmental impact assessment reports and project completion approvals, discharge fee data, and responses to public information requests.

${ }^{3}$ On May 1, 2008, Open Environmental Information measures came into effect. The Ministry of Environmental Protection requires governments to disclose information on environmental laws, regulations, and standards.

${ }^{4}$ Information source: http://www.zhaozhou.gov.cn/zhengminhudong/12380jubaowangzhan/faguizhidu/61733.html
} 


\begin{tabular}{|c|c|c|c|c|c|c|c|}
\hline & & & Mean & Std. & Min & Max & Obs. \\
\hline Dependent & An aggregative pollution & An integrated index with wastewater emissions, $\mathrm{SO}_{2}$ & 0.35 & 0.87 & -3.03 & 2.16 & 1017 \\
\hline \multirow[t]{3}{*}{ variable } & index, Pollution & emissions, smoke emissions, and $\mathrm{PM}_{2.5}$ inhalable & & & & & \\
\hline & & particles in the sample cities using a principal & & & & & \\
\hline & & component analysis method & & & & & \\
\hline Independent & High-speed railways (HSRs), & HSRs dummy variable & 0.57 & 0.50 & 0.00 & 1.00 & 1017 \\
\hline \multirow[t]{4}{*}{ variable } & $H S R$ & & & & & & \\
\hline & Population density, & Number of people per unit area in an administrative & 6.03 & 0.82 & 3.68 & 7.84 & 1017 \\
\hline & Popu_density* & region $\left(1000\right.$ people $\left./ \mathrm{km}^{2}\right)$ & & & & & \\
\hline & Industrial structure, & Proportion of secondary industry in GDP (\%) & 3.91 & 0.21 & 3.18 & 4.38 & 1017 \\
\hline \multirow{6}{*}{$\begin{array}{l}\text { Control } \\
\text { variables }\end{array}$} & Second industry & & & & & & \\
\hline & Ratio of Foreign direct & Proportion of FDI in GDP $(\%)$ & 0.14 & 0.14 & 0.01 & 0.59 & 1017 \\
\hline & investment (FDI) to GDP, FDI & & & & & & \\
\hline & Number of Internet users, $\mathrm{Net}^{*}$ & Number of internet users (households) & 4.18 & 0.98 & 1.99 & 7.34 & 1017 \\
\hline & Economic development, $\mathrm{Per}$ & Square term of logarithm per capita GDP & 2.05 & 0.38 & 1.05 & 2.88 & 1017 \\
\hline & capita GDP* & & & & & & \\
\hline Mediating & Pollution information & Pollution information transparency index & 3.68 & 0.43 & 2.58 & 4.36 & 1017 \\
\hline variable & transparency index, $P I T I^{*}$ & & & & & & \\
\hline Moderator & Political promotion incentives, & Dummy variable $=1$ if mayor' age $<=57$, otherwise,$=$ & 0.73 & 0.44 & 0.00 & 1.00 & 1017 \\
\hline variable & Pro_incent & 0 & & & & & \\
\hline
\end{tabular}

$296 *$ These variables were used in logarithmic form. For variables that were measured as numbers, this took the form log

297 (variable +1$)$.

298 The correlation matrix for all variables is described in Table 2. These variables were used in logarithmic

299 form, except for the dummy variable. The correlation coefficient is lower than 0.60. Additionally, the maximum

300 variance inflation factor (VIF) in the regression is 3.12, which is lower than the critical threshold value of 10

301 (Giorgio and Bedogni, 2010). This indicates that there was no multicollinearity problem.

Table 2 Statistical description of the main variables

\begin{tabular}{lllllllllll}
\hline Variables & $\mathbf{1}$ & $\mathbf{2}$ & $\mathbf{3}$ & $\mathbf{4}$ & $\mathbf{5}$ & $\mathbf{6}$ & $\mathbf{7}$ & $\mathbf{8}$ & $\mathbf{9}$ \\
\hline 1. Pollution & 1.00 & & & & & & & & & \\
\hline
\end{tabular}




\begin{tabular}{|c|c|c|c|c|c|c|c|c|c|}
\hline 2. $H S R$ & -0.13 & 1.00 & & & & & & & \\
\hline 3.Popu_density & 0.01 & 0.38 & 1.00 & & & & & & \\
\hline 4. Second industry & 0.25 & -0.27 & -0.10 & 1.00 & & & & & \\
\hline 5. FDI & -0.02 & 0.26 & 0.51 & -0.21 & 1.00 & & & & \\
\hline 6. Net & 0.11 & 0.47 & 0.58 & -0.37 & 0.54 & 1.00 & & & \\
\hline 7. Per capita GDP & 0.01 & 0.02 & 0.00 & -0.01 & 0.04 & 0.02 & 1.00 & & \\
\hline 8. PITI & -0.13 & 0.35 & 0.46 & -0.22 & 0.41 & 0.54 & 0.02 & 1.00 & \\
\hline 9. Pro_incent & -0.09 & -0.12 & -0.21 & 0.16 & -0.20 & -0.29 & 0.00 & -0.19 & 1.00 \\
\hline
\end{tabular}

\subsection{Methodology}

The DID model is adopted in this study because the introduction of an HSR is a part of a national-level strategic plan, which can be regarded as a quasi-natural experiment. To explore the relationship between the introduction of an HSR and pollution, we should not only compare the effect of introduction of an HSR on pollution before and after the introduction of HSR in a city but also consider the common trend of the treated groups (cities with HSRs in the observation period) and untreated groups (cities without HSRs in the observation period). Other factors, such as macroeconomic and local environmental policies, could affect pollution and should be ignored. DID is an appropriate method for analyzing policy effects and has been widely used in the quantitative evaluation of public policy or project implementation effects in econometrics. Compared to other methods in evaluating policy effects, the DID method can maximally solve the endogeneity problem and avoid reverse causality, which is more scientific and accurate in estimating the policy effect. The DID framework allows us to control the differences in pollution emissions before and after the introduction of HSR and the variations in pollution emissions of cities with and without HSR. The DID model controls the fixed effect of time and individual fixed effects of the city. The baseline regression model (Model 1) built in this study is

$$
\text { Pollution }_{i t}=\alpha_{i}+\delta_{t}+\beta_{1} H S R_{i t}+\gamma \sum X_{i t}+\varepsilon_{i t}
$$
and year fixed effects, respectively; $\sum X_{i t}$ is control variables; and $\varepsilon_{\mathrm{it}}$ is an error term. Because the specification includes city and year fixed effects, it is not necessary to include a noninteraction treatment or a period dummy variable. The estimate of the effect of HSR on pollution is $\beta_{1}$. 
HSR is significant, the introduction of HSR has a significant influence on environmental pollution, and we proceed to the next step. In the second step, the relationship between environmental regulations and HSR was examined. If the coefficient of HSR is significant, the introduction of HSR has a significant influence on environmental regulations. In the third step, both HSR and PITI are included in the regression. If the coefficient of PITI is significant and the coefficient of HSR becomes insignificant, there is a complete mediating effect. However, if the coefficient of PITI is significant, and the coefficient of HSR remains significant, the partially mediating effect is significant. The three-step hierarchical regression method (Model 2) is expressed as follows:

Step 1. Examining the impact of the introduction of HSR on environmental pollution:

$$
\text { Pollution }_{i t}=\alpha_{i}+\delta_{t}+\beta_{1} H S R_{i t}+\gamma \sum X_{i t}+\varepsilon_{i t} \text {. }
$$

Step 2. Testing the impact of the introduction of HSR on environmental regulations:

$$
P I T I_{i t}=\alpha_{i}+\delta_{t}+\beta_{1} H S R_{i t}+\gamma \sum X_{i t}+\varepsilon_{i t}
$$

Step 3. Putting HSR and PITI into the regression equation:

$$
\text { Pollution }_{i t}=\alpha_{i}+\delta_{t}+\beta_{1} H_{S R}+\beta_{2} \text { PITI }_{i t}+\gamma \sum X_{i t}+\varepsilon_{i t}
$$

To examine the moderated mediation effects of officials' political promotion incentives on the relationship between environmental regulations and environmental pollution, hierarchical regression was applied (James and Brett, 1984). In the first step, the relationship between the introduction of HSRs and officials' political promotion incentives was tested. If the coefficient of $H S R$ is significant, we proceed to the next step. In the second step, the relationship between environmental regulations, the introduction of HSRs, and officials' political promotion incentives is examined. If the coefficient of $H S R$ is significant, we proceed to the third step. In the third step, the relationship among pollution, the introduction of HSR, environmental regulations, and regulations and political promotion incentives is added. According to Edwards and Lambert (2007) giving out methods for integrating moderation and mediation, if the coefficient of the interaction term is significant, the moderated mediation effect of political promotion incentives is significant. The model (Model 3) of the fourstep method above is expressed as follows:

Step 1. Examining the impact of the introduction of HSRs and political promotion incentives on environmental pollution: 


$$
\text { Pollution }_{i t}=\alpha_{i}+\delta_{t}+\beta_{1} H_{S S R_{i t}}+\beta_{2} \operatorname{Pr} o_{-} \text {incentives }_{i t}+\gamma \sum X_{i t}+\varepsilon_{i t}
$$

Step 2. Testing the impact of the introduction of HSR and officials' political promotion incentives on environmental regulations:

$$
\text { PITI }_{i t}=\alpha_{i}+\delta_{t}+\beta_{1} \text { HSR }_{i t}+\beta_{2} \operatorname{Pr} o_{-} \text {incentives }_{\mathrm{it}}+\gamma \sum X_{i t}+\varepsilon_{i t}
$$

Step 3. Putting HSR, Pro_incent, and PITI into the regression equation:

$$
\text { Pollution }_{i t}=\alpha_{i}+\delta_{t}+\beta_{1} H_{S S R_{i t}}+\beta_{2} \operatorname{Pr} o_{-} \text {incentives }_{\mathrm{it}}+\beta_{3} \text { PITI }_{i t}+\gamma \sum X_{i t}+\varepsilon_{i t}
$$

Step 4. Putting HSR, Pro_incent, PITI, and the interaction term PITI×Pro_incent into the regression equation:

$$
\text { Pollution }_{i t}=\alpha_{i}+\delta_{t}+\beta_{1} \text { HSR }_{i t}+\beta_{2} \operatorname{Pr} o_{-} \text {incentives }_{\mathrm{it}}+\beta_{3} \text { PITI }_{i t}++\beta_{4} \text { PITI }_{i t} \times \operatorname{Pr} o_{-} \text {incentives }_{i t}+\gamma \sum X_{i t}+\varepsilon_{i t}
$$

\section{Empirical results and discussion}

\subsection{Benchmark regression result}

The benchmark regression results, based on Equation 1, are presented in Table 3. Column (1) shows the regression results only with the control variables. We added the independent variable HSR in column (2) to test the influence of the introduction of HSRs on industrial pollution emissions. We found that the coefficient of HSR is significantly negative $(\beta=-0.2268, p<0.01)$, which implies that the introduction of HSRs reduces environmental pollution by $22.68 \%$.

Table 3 Benchmark regression result

\begin{tabular}{lcc}
\hline & \multicolumn{1}{c}{$(\mathbf{1})$} & $(\mathbf{2})$ \\
\hline Variables & Pollution & Pollution \\
HSR & & $-0.2268 * * *$ \\
& & $(-4.69)$ \\
Popu_density & $-0.1650^{*}$ & $-0.1598^{*}$ \\
& $(-1.75)$ & $(-1.71)$ \\
Second industry & $2.5025 * * *$ & $2.2757 * * *$ \\
& $(8.82)$ & $(7.98)$ \\
& $-1.1627 * * *$ & $-0.8941^{* *}$ \\
& $(-2.90)$ & $(-2.29)$ \\
& 15 &
\end{tabular}




$\begin{array}{lcc}\text { Net } & 0.1851 * * * & 0.2361 * * * \\ & (2.77) & (3.54) \\ \text { Per capita GDP } & -0.0202 & -0.0219 \\ & (-0.35) & (-0.39) \\ \text { PITI } & & \\ & & \\ \text { Constant } & -9.3433^{* * * *} & -8.4880^{* * *} \\ & (-7.67) & (-7.13) \\ & \text { YES } & \text { YES } \\ \text { Year fixed } & \text { YES } & \text { YES } \\ \text { City fixed } & 1017 & 1017 \\ N & & \\ R^{2} & & \end{array}$

Note: Two-tailed; Standard errors in parentheses; Year dummy and City dummy were controlled for; Some observations were excluded from the regression due to missing lag variables; VIF was lower than $10 ; t$-statistics in parentheses; $* p<0.10, * * p<0.05, * * * p<0.01$.

\subsection{Parallel trend test using the DID method}

A parallel trend test using the DID method is necessary because we need to ensure that the developing trend of the treated group and the untreated group is parallel before they receive the policy shock. In our test, we generate a group of time trend dummy variables to test the parallel trend before and after the introduction year of an HSR. The model is expressed in Eq. (9)

$$
\text { Pollution }_{i t}=\alpha_{i}+\delta_{t}+\sum_{k=1}^{4} \beta_{1} \text { first_HSR }_{i, t-k}+\sum_{z=1}^{4} \beta_{1} \text { first_HSR }_{i, t+z}+\gamma \sum X_{i t}+\varepsilon_{i t} \text {, }
$$
where first_HSR $_{i, t}$ is a dummy variable indicating whether a city $i$ is first connected to an HSR network in year $t$. It switches to 1 only if the HSR line connecting the city $i$ is opened in year $t$; otherwise, it is set to 0 . Here, first_HSR $R_{i, t-k}$ represents the $k(k=1,2,3,4)$ years before the HSR is first connected. If the observation unit includes the data from years $k$ before the policy impact, the unit is set to 1 ; otherwise, it is set to 0 . Here, first_HSR $R_{i, t+z}$ represents the $z(z=1,2,3,4)$ years after the HSR is first connected. If the observation unit includes the data from $z$ years after the policy impact, the unit is set to 1 ; otherwise, it is set 
to 0 .

The parallel trend test results are presented in Table 4. We found that the regression coefficient of HSR is not significant in the 4 years before the introduction of HSR. After the HSR is introduced, the regression coefficient of the HSR is significantly negative, indicating that the introduction of an HSR influences pollution and the DID parallel trend assumption is satisfied. Based on the benchmark regression result and parallel trend test, we can verify that the introduction of an HSR can reduce pollution emissions, and hypothesis 1 is supported.

Table 4 Parallel trend test results

\begin{tabular}{|c|c|}
\hline Variables & Pollution \\
\hline \multirow[t]{2}{*}{ first_HSR $R_{i, t+4}$} & $-0.2917 * *$ \\
\hline & $(-2.36)$ \\
\hline \multirow{2}{*}{ first_HSR $R_{i, t+3}$} & $-0.5081^{* * *}$ \\
\hline & $(-4.18)$ \\
\hline \multirow[t]{2}{*}{ first_$_{-} H S R_{i, t+2}$} & $-0.9412 * * *$ \\
\hline & $(-8.68)$ \\
\hline \multirow[t]{2}{*}{ first_$_{-} H S R_{i, t+1}$} & $-0.7745 * * *$ \\
\hline & $(-6.72)$ \\
\hline \multirow[t]{2}{*}{ first_$_{-} H S R_{i, t}$} & $-0.8210 * * *$ \\
\hline & $(-6.78)$ \\
\hline \multirow[t]{2}{*}{ first_HSR $R_{i, t-1}$} & -0.0746 \\
\hline & $(-0.40)$ \\
\hline \multirow[t]{2}{*}{ first_$_{-} H S R_{i, t-2}$} & -0.0318 \\
\hline & $(-0.16)$ \\
\hline \multirow[t]{2}{*}{ first_HSR $R_{i, t-3}$} & -0.1992 \\
\hline & $(-0.99)$ \\
\hline \multirow[t]{2}{*}{ first_HSR $R_{i, t-4}$} & -0.1624 \\
\hline & $(-0.86)$ \\
\hline Control variables & YES \\
\hline Year fixed & YES \\
\hline City fixed & YES \\
\hline
\end{tabular}


Note: Two-tailed; Standard errors in parentheses; year dummy and City dummy were controlled for; Some observations were excluded from the regression due to missing lag variables; the variance inflation factor (VIF) was lower than 10 ; $t$ statistics are in parentheses; $* p<0.10, * * p<0.05, * * * p<0.01$.

\subsection{Testing the mediating effect of environmental regulations on the relationship between HSR and pollution emissions}

Hypothesis 2 predicts that the introduction of HSRs can promote the effective implementation of environmental regulations. hypothesis 3 predicted that environmental regulations can reduce environmental pollution. hypothesis 4 predicted that environmental regulations can mediate the relationship between environmental regulations and environmental pollution. To test hypotheses $2-4$, the multiple regression results with model 2 , based on Eqs. (2)- (4), are presented in Table 5. In column (2), we examine the impact of HSRs on environmental pollution. The coefficient of HSR is significantly negative $(\beta=-0.2268, p<0.01)$, which indicates that HSRs can reduce pollution emissions. In column (3), we examine the impact of HSRs on environmental regulations. The coefficient of $H S R$ is significantly positive $(\beta=0.2349, p<0.01)$, which implies that the introduction of HSRs can improve environmental regulations. Hypothesis 3 was verified. In column (4), we placed the independent variable $H S R$ and the mediating variable PITI into a regression. The coefficient of PITI is significantly negative $(\beta=-0.1079, p<0.01)$, as well as the coefficient of $H S R(\beta=-0.2048, p<0.01)$. Moreover, the absolute value of the coefficient of HSR in column (4) is smaller than the absolute value of the coefficient of $H S R$ in column (2), which indicates that environmental regulations can reduce environmental pollution and environmental regulations has a partially mediating effect on the relationship between HSRs and environmental pollution. Therefore, hypotheses 2 and 4 were verified.

Table 5 Multiple regression results for mediating effects

\begin{tabular}{lcccc}
\hline & $(\mathbf{1})$ & $(\mathbf{2})$ & $(\mathbf{3})$ & $\mathbf{( 4 )}$ \\
\hline Variables & Pollution & Pollution & PITI & Pollution \\
HSR & & $-0.2268^{* * * *}$ & $0.2349^{* * * *}$ & $-0.2048^{* * *}$ \\
& & $(-4.69)$ & $(4.75)$ & $(-4.23)$ \\
& & & & \\
Popu_density & $-0.1650^{*}$ & $-0.1598^{*}$ & $0.1915^{* * *}$ & -0.1126
\end{tabular}




\begin{tabular}{|c|c|c|c|c|}
\hline & $(-1.75)$ & $(-1.71)$ & $(3.43)$ & $(-1.47)$ \\
\hline \multirow[t]{2}{*}{ Second industry } & $2.5025 * * *$ & $2.2757 * * *$ & $-0.1608 * * *$ & $0.4378 * * *$ \\
\hline & $(8.82)$ & (7.98) & $(-3.44)$ & $(7.48)$ \\
\hline \multirow[t]{2}{*}{$F D I$} & $-1.1627 * * *$ & $-0.8941 * *$ & 0.1984 & $-0.8355^{* *}$ \\
\hline & $(-2.90)$ & $(-2.29)$ & $(0.48)$ & $(-2.20)$ \\
\hline \multirow[t]{2}{*}{$\mathrm{Net}$} & $0.1851 * * *$ & $0.2361 * * *$ & $0.3106^{* * *}$ & $0.2693 * * *$ \\
\hline & $(2.77)$ & $(3.54)$ & $(4.02)$ & $(4.05)$ \\
\hline \multirow[t]{2}{*}{ Per capita GDP } & -0.0202 & -0.0219 & 0.0305 & -0.0047 \\
\hline & $(-0.35)$ & $(-0.39)$ & $(1.30)$ & $(-0.21)$ \\
\hline \multirow[t]{2}{*}{ PITI } & & & & $-0.1079 * * *$ \\
\hline & & & & $(-3.92)$ \\
\hline \multirow[t]{2}{*}{ Constant } & $-9.3433 * * *$ & $-8.4880 * * *$ & $-0.2043^{* *}$ & $0.3915 * * *$ \\
\hline & $(-7.67)$ & $(-7.13)$ & $(-2.53)$ & $(4.40)$ \\
\hline Year fixed & YES & YES & YES & YES \\
\hline City fixed & YES & YES & YES & YES \\
\hline$N$ & 1017 & 1017 & 1017 & 1017 \\
\hline$R^{2}$ & 0.2260 & 0.2385 & 0.1252 & 0.2400 \\
\hline
\end{tabular}
were excluded from the regression due to missing lag variables; VIF was lower than $10 ; t$-statistics in parentheses; $* p<0.10, * * p<0.05, * * * p<0.01$.

\subsection{Testing the moderated mediation effect of promotion incentives on the relationship between} environmental regulations and environmental pollution

Multiple regression results based on Eqs. (5)- (8) for the moderating mediation effect test are shown in Table 6. In column (1), we examine the impact of HSRs on environmental pollution, and the coefficient of $H S R$ is

411 significantly negative $(\beta=-0.2272, p<0.01)$. In column $(2)$, we examine the impact of the introduction of 412 HSRs on environmental regulations, and the coefficient of $H S R$ is significantly positive $(\beta=0.2312, p<0.01)$.

413 In column (3), we place the independent variable HSR and the mediating variable PITI into a regression. The 414 coefficient of PITI is significantly negative $(\beta=--0.1063, p<0.01)$, as well as the coefficient of HSR ( $\beta=-$ $4150.2057, p<0.01)$. These three steps indicate that environmental regulations have a mediating effect on the 
416 relationship between the introduction of HSRs and environmental pollution. In column (4), the coefficient of

417 the interaction term $(P I T I \times$ Pro_incent $)$ is significantly negative $(\beta=-0.0429, p<0.05)$. The coefficient of $\mathrm{R}^{2}$

418 increased from 0.2410 in column (3) to 0.2552 in column (4). The moderating effect is plotted in Figure 3 . It

419 can be observed that officials' political promotion incentives positively moderate the relationship between

420 environmental regulations and environmental pollution and further positively moderate the indirect relationship

421 between the HSRs and environmental pollution via the mediation effect of environmental regulations. We

422 presented a path diagram with a path coefficient that quantitatively and visually reveals the relationships

423 between the variables in Figure 4. The path coefficient is the regression coefficient between variables.

Table 6 Multiple regression results for moderator effects

\begin{tabular}{|c|c|c|c|c|}
\hline & (1) & (2) & (3) & (4) \\
\hline Variables & Pollution & PITI & Pollution & Pollution \\
\hline \multirow[t]{2}{*}{$H S R$} & $-0.2272 * * *$ & $0.2312 * * *$ & $-0.2057 * * *$ & $-0.2056 * * *$ \\
\hline & $(-4.68)$ & $(4.61)$ & $(-4.24)$ & $(-4.27)$ \\
\hline \multirow[t]{2}{*}{ Popu_density } & $-0.1292 *$ & $0.1886^{* * *}$ & -0.1114 & -0.1093 \\
\hline & $(-1.68)$ & $(3.45)$ & $(-1.45)$ & $(-1.42)$ \\
\hline \multirow[t]{2}{*}{ Second industry } & $0.4610 * * *$ & $-0.1505^{* * *}$ & $0.4318 * * *$ & $0.4278 * * *$ \\
\hline & $(7.80)$ & $(-3.19)$ & $(7.35)$ & (7.27) \\
\hline \multirow[t]{2}{*}{$F D I$} & $-0.8467 * *$ & 0.2336 & $-0.8002 * *$ & $-0.7517 * *$ \\
\hline & $(-2.18)$ & $(0.55)$ & $(-2.12)$ & $(-2.01)$ \\
\hline \multirow[t]{2}{*}{ Net } & $0.2365 * * *$ & $0.3006^{* * *}$ & $0.2724 * * *$ & $0.2799 * * *$ \\
\hline & $(3.56)$ & $(3.91)$ & $(4.06)$ & $(4.15)$ \\
\hline \multirow[t]{2}{*}{ Per capita GDP } & -0.0079 & 0.0288 & -0.0043 & -0.0053 \\
\hline & $(-0.36)$ & $(1.21)$ & $(-0.20)$ & $(-0.24)$ \\
\hline \multirow[t]{2}{*}{ PITI } & & & $-0.1063 * * *$ & $-0.1108 * * *$ \\
\hline & & & $(-3.90)$ & $(-4.19)$ \\
\hline \multirow[t]{2}{*}{ Pro_incent } & 0.0619 & $-0.1788 * * *$ & 0.0424 & 0.0523 \\
\hline & $(1.11)$ & $(-2.67)$ & $(0.77)$ & $(0.94)$ \\
\hline \multirow[t]{2}{*}{ PITI $\times$ Pro_incent } & & & & $-0.0429 * *$ \\
\hline & & & & $(-2.12)$ \\
\hline
\end{tabular}




\begin{tabular}{lcccc} 
Constant & $0.3805 * * *$ & -0.1307 & $0.3791 * * *$ & $0.3882 * * *$ \\
& $(4.03)$ & $(-1.57)$ & $(4.13)$ & $(4.29)$ \\
Yearfixed & YES & YES & YES & YES \\
City fixed & YES & YES & YES & YES \\
$N$ & 1017 & 1017 & 1017 & 1017 \\
$R^{2}$ & 0.2395 & 0.1373 & 0.2410 & 0.2552 \\
\hline
\end{tabular}

Note: Two-tailed; Standard errors in parentheses; Year dummy and City dummy were controlled for; Some

observations were excluded from the regression due to missing lag variables; VIF was lower than 10 ; $t$-statistics in parentheses; $* p<0.10, * * p<0.05, * * * p<0.01$.

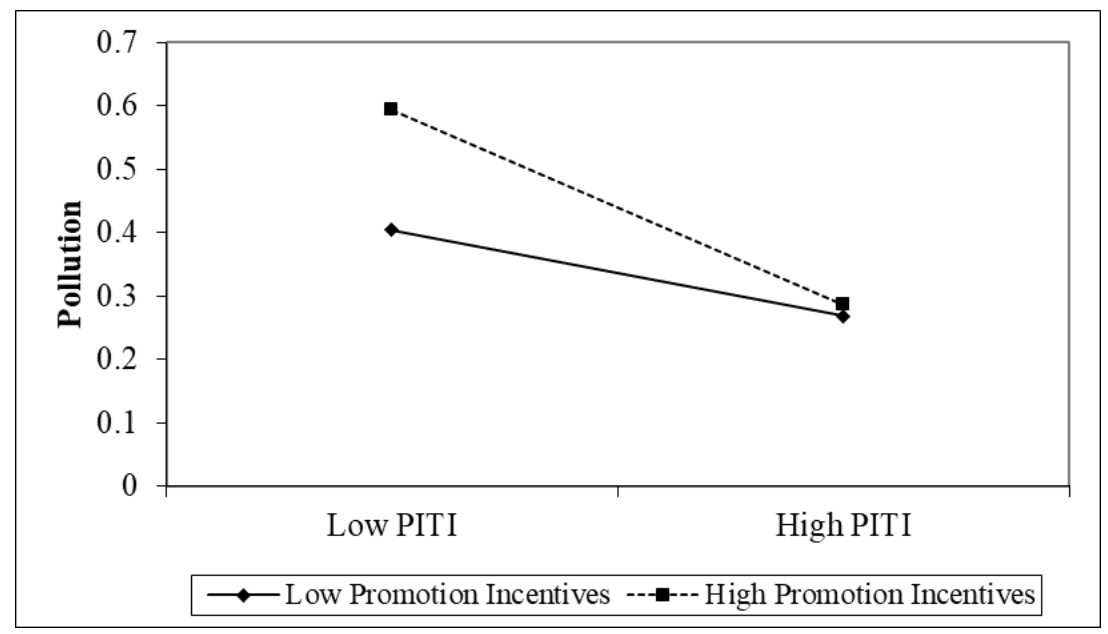

Figure 3 Moderating effects of political promotion incentives on the relationship between environmental regulations and environmental pollution

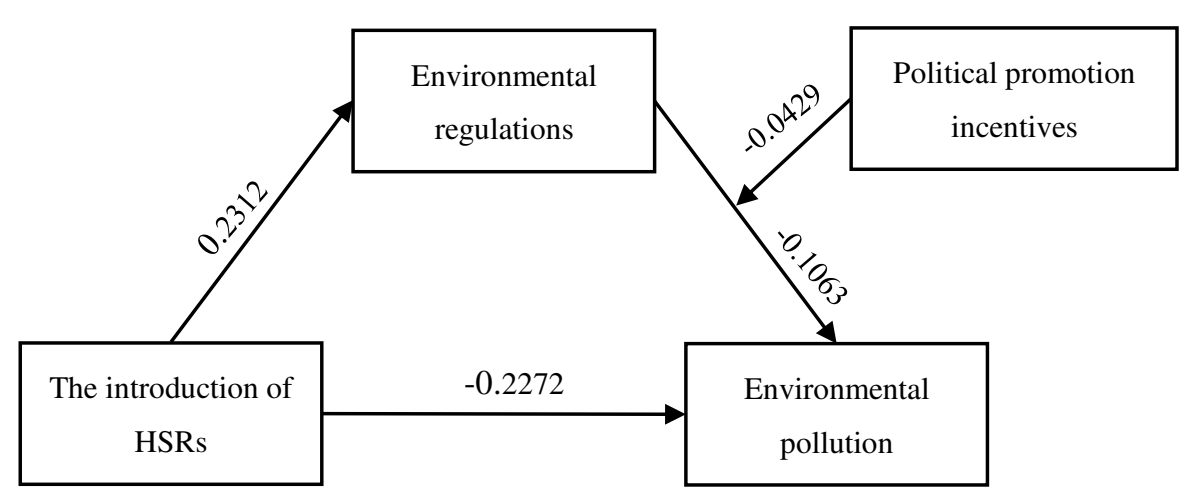

Figure 4 The path diagram of regression with path coefficients 
441 We used the placebo test and PSM-DID method to verify the empirical results.

\subsubsection{Placebo test}

443 The placebo test checks the baseline regression result, which demonstrates that the effect does not exist when it "should not" exist. Specifically, we test whether the positive effect of the introduction of HSRs on pollution reduction still exists if the introduction year of an $\operatorname{HSR}$ is advanced. We use the variable $F n_{-} H S R(n=3,4,5)$ representing the number of years before the HSR was introduced. If the coefficient of $F n \_H S R$ is not significant, the environmental pollution reduction is indeed caused by the introduction of HSRs; otherwise, it is caused by other unobservable factors, and the conclusion is not robust. We used Eq. (1) to finish the regression, and the results are shown in Table7. We found that the coefficient of $F n \_H S R(\mathrm{n}=3,4,5)$ is not significant, and the coefficient of $\mathrm{R}^{2}$ does not change significantly among the $F n_{-} H S R(\mathrm{n}=3,4,5)$, indicating the robustness of our baseline regression result.

Table7 Placebo test results

\begin{tabular}{lc}
\hline Variables & Pollution \\
\hline F3_HSR & -0.1197 \\
& $(-1.63)$ \\
F4_HSR & -0.0976 \\
& $(-0.94)$ \\
F5_HSR & 0.0157 \\
& $(0.14)$ \\
F3_R ${ }^{2}$ & 0.2450 \\
F4_R & 0.2441 \\
F5_R ${ }^{2}$ & YES \\
Control variables & YES \\
Yearfixed & YES \\
City fixed & 1017 \\
\hline
\end{tabular}


Propensity score matching (PSM) was used to check the baseline regression results and multiple regression results for the mediating effect. This is because cities with PITI always have more serious pollution problems, which will cause a sample selection bias when using the DID model. Heckman et al. (1998) proposed and developed the PSM-DID method, which could compensate for the inadequacy of the DID method and deal with endogenous problems. First, we used city-level variables such as population density, per capita GDP, and industrial structure as our chosen criteria. A nearest-neighbor propensity score of 1:1 between group matching strategies was used to identify the untreated group sample (to keep the sample different). As a result, we obtained unbalanced panel data (909 samples) from 2009 to 2017. Second, we used the DID model to perform a regression on this sample. The results are presented in Table 8 .

In column (2), we find that the coefficient of $H S R$ is still negatively significant $(\beta=-0.2296, p<0.01)$, which indicates that the introduction of HSRs can reduce environmental pollution. In column (3), we examine the impact of HSRs on environmental regulations. The coefficient of HSR is significantly positive $(\beta=0.2276$, $\mathrm{p}<0.01$ ), which implies that the introduction of HSRs can improve environmental regulations. In column (4), we use the independent variable $H S R$ and the mediating variable PITI in a regression. The coefficient of PITI is significantly negative $(\beta=--0.1143, \mathrm{p}<0.01)$, as well as the coefficient of $\operatorname{HSR}(\beta=-0.2062, \mathrm{p}<0.01)$. Moreover, the absolute value of the coefficient of HSR in column (4) is smaller than the absolute value of the coefficient of HSR in column (2). This indicates that environmental regulations can reduce environmental pollution and environmental regulations have a partially mediating effect on the relationship between HSRs and environmental pollution. The robust check results support our empirical results.

Table 8 Results of robustness check using the PSM-DID method

\begin{tabular}{lcccc}
\hline \multicolumn{1}{c}{$(\mathbf{1})$} & $\mathbf{( 2 )}$ & $\mathbf{( 3 )}$ & $\mathbf{( 4 )}$ \\
\hline Variables & Pollution & Pollution & PITI & Pollution \\
HSR & & $-0.2296^{* * * *}$ & $0.2276^{* * *}$ & $-0.2062^{* * *}$ \\
& & $(-4.60)$ & $(4.50)$ & $(-4.15)$ \\
Popu_density & $-0.2305^{* *}$ & $-0.1945^{*}$ & $0.2344 * * *$ & -0.1343 \\
& $(-2.23)$ & $(-1.86)$ & $(3.46)$ & $(-1.57)$ \\
Second industry & $2.5222^{* * *}$ & $2.2339 * * *$ & $-0.1405^{* * *}$ & $0.4320 * * *$ \\
& $(7.91)$ & $(6.83)$ & $(-2.69)$ & $(6.57)$
\end{tabular}




\begin{tabular}{|c|c|c|c|c|}
\hline \multirow[t]{2}{*}{$F D I$} & $-0.9058 * *$ & -0.6320 & 0.1373 & -0.5740 \\
\hline & $(-2.28)$ & $(-1.64)$ & $(0.32)$ & $(-1.55)$ \\
\hline \multirow[t]{2}{*}{$\mathrm{Net}$} & $0.1791 * * *$ & $0.2370^{* * *}$ & $0.3087 * * *$ & $0.2414 * * *$ \\
\hline & (2.59) & $(3.41)$ & (4.29) & $(3.97)$ \\
\hline \multirow[t]{2}{*}{ Per capita GDP } & -0.0171 & -0.0194 & 0.0241 & -0.0041 \\
\hline & $(-0.28)$ & $(-0.33)$ & $(1.01)$ & $(-0.18)$ \\
\hline \multirow[t]{2}{*}{ PITI } & & & & $-0.1143 * * *$ \\
\hline & & & & $(-3.73)$ \\
\hline \multirow[t]{2}{*}{ Constant } & $-8.9531 * * *$ & $-8.0803 * * *$ & $-0.1768 * *$ & $0.4531 * * *$ \\
\hline & $(-6.87)$ & $(-6.36)$ & $(-2.17)$ & $(5.05)$ \\
\hline Year fixed & YES & YES & YES & YES \\
\hline City fixed & YES & YES & YES & YES \\
\hline$N$ & 909 & 909 & 909 & 909 \\
\hline$R^{2}$ & 0.2126 & 0.2292 & 0.1230 & 0.2312 \\
\hline
\end{tabular}

477 Note. Two-tailed; Standard errors in parentheses; Year dummy and City dummy were controlled for; Some observations were excluded from the regression due to missing lag variables; VIF was lower than $10 ; t$-statistics in parentheses; * $p<$ $0.10, * * p<0.05, * * * p<0.01$.

481 We changed the proxy of the moderator variable, political turnover, to check the moderator mediation effect. Political turnover indicates that mayors are placed in either more important (still at the mayoral level) or higherranked (vice-provincial level) positions, retiring, being transferred to another position at the same rank, or termination. If a mayor is promoted, we regard his or her political promotion incentive as strong, and Pro_incent is set to 1; otherwise, we regard his or her political promotion incentives as poor, and Pro_incent is set at 0.

Table 9 shows robustness check result. In column (1), we examine the impact of HSRs on environmental pollution, and the coefficient of $H S R$ is significantly negative $(\beta=-0.2181, p<0.01)$. In column $(2)$, we examine the impact of HSRs on environmental regulations, and the coefficient of $H S R$ is significantly positive $(\beta=$ $0.2309, p<0.01)$. In column (3), we place the independent variable $H S R$ and the mediating variable PITI into a regression. The coefficient of PITI is significantly negative $(\beta=-0.1067, p<0.01)$, as well as the coefficient of $\operatorname{HSR}(\beta=-0.1971, p<0.01)$. In column $(4)$, the interaction term $(P I T I \times$ Pro_incent $)$ is added in the regression 
492 and the coefficient of interaction term is significantly negative $(\beta=-0.0497, p<0.05)$. The coefficient of $\mathrm{R}^{2}$

493 increased from 0.2463 in column (3) to 0.2564 in column (4). The robust check result supports the empirical

494 moderated mediation effect result. In addition, the moderating effect is plotted in Figure 5, which also shows

495 that official's political incentives positively moderated the relationship between environmental regulations and 496 environmental pollution.

Table 9 Robustness check results for moderator effects

\begin{tabular}{|c|c|c|c|c|}
\hline & (1) & (2) & (3) & (4) \\
\hline Variables & Pollution & PITI & Pollution & Pollution \\
\hline \multirow[t]{2}{*}{$H S R$} & $-0.2181 * * *$ & $0.2309 * * *$ & $-0.1971 * * *$ & $-0.2075^{* * *}$ \\
\hline & $(-4.58)$ & (4.64) & $(-4.15)$ & $(-4.52)$ \\
\hline \multirow[t]{2}{*}{ Popu_density } & $-0.1343^{*}$ & $0.1932 * * *$ & -0.1157 & -0.1140 \\
\hline & $(-1.75)$ & $(3.41)$ & $(-1.51)$ & $(-1.48)$ \\
\hline \multirow[t]{2}{*}{ Second industry } & $0.4669 * * *$ & $-0.1617 * * *$ & $0.4351 * * *$ & $0.4349 * * *$ \\
\hline & (7.94) & $(-3.43)$ & (7.47) & (7.48) \\
\hline \multirow[t]{2}{*}{$F D I$} & $-0.8833^{* *}$ & 0.1938 & $-0.8254 * *$ & $-0.7653 * *$ \\
\hline & $(-2.26)$ & $(0.47)$ & $(-2.18)$ & $(-2.06)$ \\
\hline \multirow[t]{2}{*}{ Net } & $0.2216^{* * *}$ & $0.3147 * * *$ & $0.2592 * * *$ & $0.2635 * * *$ \\
\hline & (3.35) & (4.04) & (3.88) & (3.99) \\
\hline \multirow[t]{2}{*}{ Per capita GDP } & -0.0094 & 0.0309 & -0.0056 & -0.0048 \\
\hline & $(-0.43)$ & $(1.32)$ & $(-0.26)$ & $(-0.22)$ \\
\hline \multirow[t]{2}{*}{ PITI } & & & $-0.1067 * * *$ & $-0.1565 * * *$ \\
\hline & & & $(-3.89)$ & $(-5.27)$ \\
\hline \multirow[t]{2}{*}{ Pro_incent } & 0.1181 & -0.0421 & 0.1120 & 0.1002 \\
\hline & (1.55) & $(-0.52)$ & (1.53) & (1.33) \\
\hline \multirow[t]{2}{*}{ PITI $\times$ Pro_incent } & & & & $-0.0497 * *$ \\
\hline & & & & $(-2.23)$ \\
\hline \multirow[t]{2}{*}{ Constant } & $0.3324 * * *$ & $-0.1783^{*}$ & $0.3280 * * *$ & $0.3450 * * *$ \\
\hline & $(3.43)$ & $(-1.86)$ & $(3.49)$ & $(3.74)$ \\
\hline Year fixed & YES & YES & YES & YES \\
\hline
\end{tabular}




\begin{tabular}{lcccc} 
City fixed & YES & YES & YES & YES \\
$N$ & 1017 & 1017 & 1017 & 1017 \\
$R^{2}$ & 0.2453 & 0.1265 & 0.2463 & 0.2504 \\
\hline
\end{tabular}

Note: Two-tailed; Standard errors in parentheses; Year dummy and City dummy were controlled for; Some observations were excluded from the regression due to missing lag variables; VIF was lower than $10 ; t$-statistics in parentheses; $* p<0.10, * * p<0.05, * * * p<0.01$.

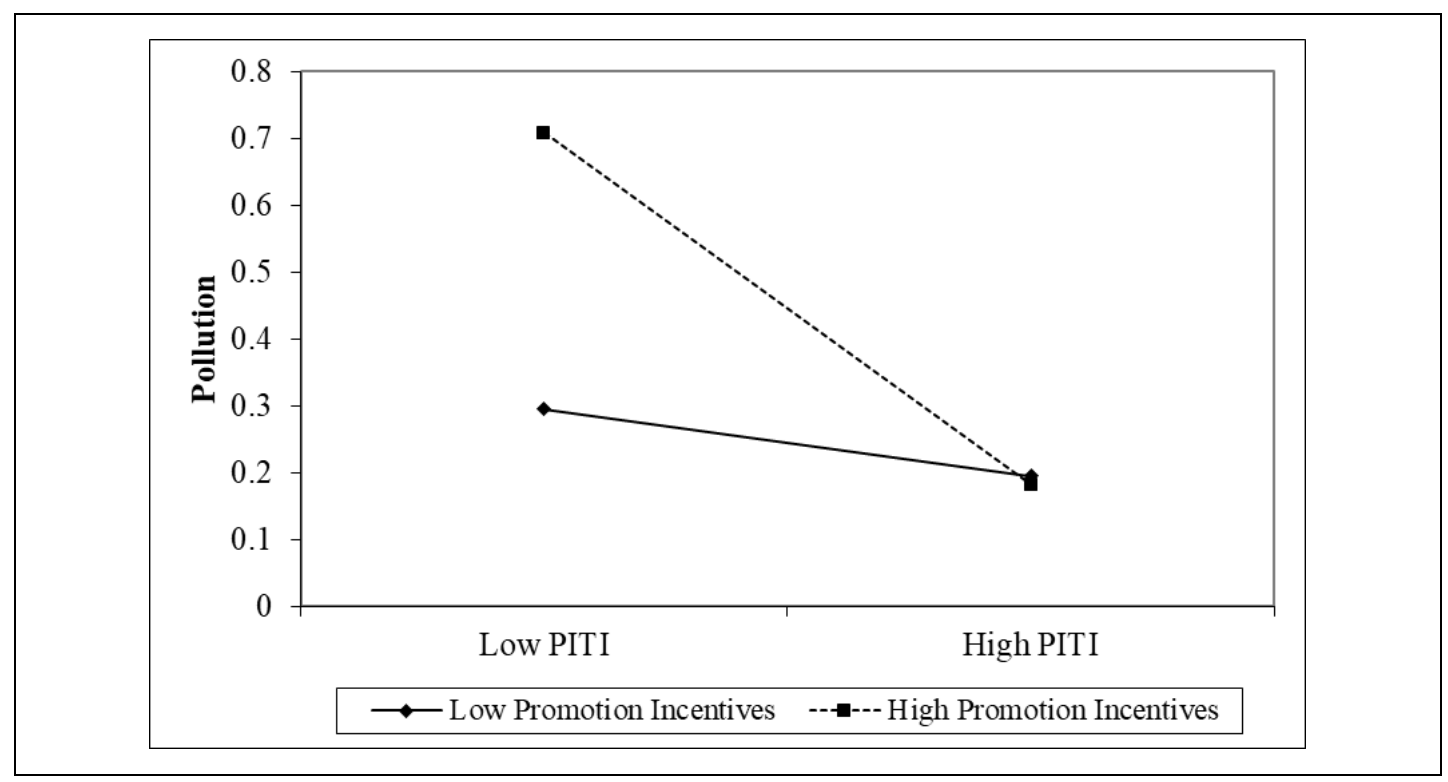

Figure 5 Moderating effects of promotion incentives on the relationship between environmental regulations and environmental pollution

\section{Conclusion and policy implication}

Developing countries face severe environmental pollution problems, and reducing environmental pollution is an urgent task. As a green and environmentally friendly transportation tool, HSRs have benefited the economy, tourism, and urban development. The ways in which the introduction of HSRs directly reduces environmental pollution have been explored in various papers. However, the indirect effect of the introduction of HSRs on environmental pollution and its mechanism has not been thoroughly investigated. With a balanced panel of 113 cities in China from 2009 to 2017, using the DID method and hierarchical regression model, this empirical study explores the influence of HSRs on environmental pollution via environmental regulations' mediation effect. Additionally, the moderated mediation effect of officials' political promotion incentives is discussed.

The empirical finding shows that the introduction of HSRs can reduce pollution. The introduction of HSRs can promote the effective implementation of environmental regulations, which can reduce environmental 

pollution. Additionally, we find that political promotion incentives positively moderated the effect of environmental regulations on environmental pollution. Furthermore, officials' political promotion incentives moderate the indirect relationship between the introduction of HSR and environmental pollution through environmental regulations such that this relationship is stronger with strong political promotion incentives of a mayor. The PSM-DID method was used to address endogenous problems caused by sample selection bias. Moreover, we used the parallel trend test, placebo test, and changing the moderator variable for the robustness check. All the results show that our conclusion is reliable.

This study has important implications for policymakers. First, our results indicate that the introduction of HSRs can reduce urban environmental pollution through efficient use of technological and social advantages, harmonizing the relationship between economic development and environmental protection. Second, our results indicate that environmental regulations reduce environmental pollution. Therefore, to achieve effective pollution control, the government should strengthen environmental regulations by increasing environmental information disclosure, creating a transparent information environment, and positively responding to public participation. For example, the government can create a reward feedback plan for the public and community when these regulators contribute to environmental pollution monitoring. In a transparent information environment and with the support of the government, the public is likely to become more active, which further promotes governmental performance. Third, we found that officials'strong political promotion incentives could prompt environmental regulations, and pollution is further controlled. To improve environmental regulations, a reductions environmental pollution and increased green development could be achieved through performance evaluations and political promotion criteria.

Despite these results, our study has some limitations. The effect of the introduction of HSRs on pollution in cities is heterogeneous. The quality, length, and route of HSRs are different in the western, eastern, and central regions of China. Moreover, the effect of HSRs on cities' pollution increases with the HSR network development. Some cities that are rich in HSR lines may be more affected by the HSR network. In future studies, the heterogeneity effect of HSRs on environmental pollution will be explored. Further, changes in environmental protection that can be brought about through the introduction of a network of HSRs will be discussed.

\section{References}


Baron RM, Kenny DA (1986) The moderator-mediator variable distinction in social psychological research: Conceptual, strategic, and stastical consideration. J Pers Soc Psychol 51(6): 1173-1182.

Bo Z (1996) Economic performance and political mobility: Chinese provincial leaders. J Contemp China 5(12):135-154.

Chen R, Kan H, Chen B, Huang W, Bai Z, Song G, Pan G (2012) Association of particulate air pollution with daily mortality: the China air pollution and health effects study. Am J Epidemiol 175(11): 1173-1181.

Cohen MA, Santhakumar V (2007) Information disclosure as environmental regulation: A theoretical analysis. Environ Resour Econ 37(3):599-620.

D'Alfonso T, Jiang C, Bracaglia V (2016) Air transport and high-speed rail competition: Environmental implications and mitigation strategies. Transp Res Pt A-Policy Pract Policy Practice Digest 92A(10): 261 276.

DeVaro J (2006) Internal promotion competitions in firms. Rand J Econ 37(3): 521-542.

DiMicco JM, Hollenbach KJ, Pandolfo A, Bender W (2007) The impact of increased awareness while face-toface. Hum Compu Interact 22(1-2):47-96.

Edwards JR, Lambert LS (2007) Methods for integrating moderation and mediation: a general analytical framework using moderated path analysis. Psychol Methods 12(1):1-22.

Fan X, Xu Y, Nan Y, Li B, Cai H (2020) Impacts of high-speed railway on the industrial pollution emissions in China. Kybernetes 49(11):2713-2735.

Féres J, Reynaud A (2012) Assessing the impact of formal and informal regulations on environmental and economic performance of Brazilian manufacturing firms. Environ Resour Econ 52(1):65-85.

Gioia DA, Schultz M, Corley KG (2000) Organizational identity, image, and adaptive instability. Acad Manage Rev 25(1):63-81.

Giorgio, Bedogni (2010) Modern regression methods. J R Stat Soc Ser A-Stat Soc 173(1):275-275.

Givoni M (2006) Development and impact of the modern high-speed train: A review. Transp Rev 26(5):593611.

Glaeser EL, Mare DC (2001) Cities and skills. J Labor Econ 19(2):316-342.

Grossman GM, Krueger AB (1995) Economic growth and the environment. Q J Econ 110(2):353-377.

Grossman SJ (1981) The informational role of warranties and private disclosure about product quality. J Law Econo 24(3):461-483.

Halkos GE, Paizanos EA (2013) The effect of government expenditure on the environment: An empirical investigation. Ecol Econ 91:48-56.

He LY, Zhang HZ (2021) Spillover or crowding out? The effects of environmental regulation on residents' willingness to pay for environmental protection. Nat Hazards 105(1):611-630:

Heckman JJ, Ichimura H, Todd P (1998) Matching as an econometric evaluation estimator. Rev Econ Stud 65(2):261-294.

Hixson M, Mahmud A, Hu J, Kleeman MJ (2012) Resolving the interactions between population density and air pollution emissions controls in the San Joaquin Valley, USA. J Air Waste Manage Assoc 62(5):566-575.

Huang R, Chen D (2015) Does environmental information disclosure benefit waste discharge reduction? Evidence from China. J Bus Ethics 129(3):535-552.

James LR, Brett JM (1984) Mediators, moderators, and tests for mediation. J Appl Psychol 69(2):307-321.

Jebjerg L, Lando H (1997) Regulating a polluting firm under asymmetric information. Environ Resour Econom 10(3): 267-284.

Kahn ME, Li P, Zhao D (2015) Water pollution progress at borders: the role of changes in China's political promotion incentives. Am Econ J-Econ Policy 7(4):223-242. 
Kathuria V (2007) Informal regulation of pollution in a developing country: evidence from India. Ecol Econ 63(2-3):403-417.

Kobayashi K, Okumura M (1997) The growth of city systems with high-speed railway systems. Ann Reg Sci 31(1):39-56.

Kou CW, Tsai WH (2014) "Sprinting with small steps" towards promotion: solutions for the age dilemma in the CCP cadre appointment system. J China (71):153-171.

Li D, Cao C, Zhang L, Chen X, Ren S, Zhao Y (2017) Effects of corporate environmental responsibility on financial performance: The moderating role of government regulation and organizational slack. J Cleaner Prod 166:1323-1334.

Lin Y (2017) Travel costs and urban specialization patterns: Evidence from China's high speed railway system. J Urban Econ 98:98-123.

List JA, Co CY (2000) The effects of environmental regulations on foreign direct investment. J Environ Econ Manage 40(1):1-20.

Liu Q, Li L (2019) Spatial heterogeneity of government regulation, spatial distance and enterprise carbon information disclosure: An analysis based on the heavy pollution industry in China. Int J Environ Res Public Health 16(23):4777-4792.

Managi S, Kaneko S (2009) Environmental performance and returns to pollution abatement in China. Ecol Econ 68(6):1643-1651.

Matthew A Cole R, Kenichi Shimamoto (2005) Industrial characteristics, environmental regulations and air pollution in a developing country: An analysis of the Chinese manufacturing sector. J Environ Econ Manage 50:121-143.

Mayer H (1999) Air pollution in cities. Atmos Environ 33(24-25):4029-4037.

Millimet DL, Roy J (2016) Empirical tests of the pollution haven hypothesis when environmental regulation is endogenous. J Appl Econom 31(4):652-677.

Qi Y, Lu H, Zhang N (2019) Will environmental regulation help reduce pollution and improve efficiency? A New Era 237-268.

Rohde RA, Muller RA (2015) Air pollution in China: mapping of concentrations and sources. PLoS One 10(8):0135749.

Shen J, Wei YD, Yang Z (2017) The impact of environmental regulations on the location of pollution-intensive industries in China. J Cleaner Prod 148:785-794.

Silajdzic S, Mehic E (2017) The impact of environmental taxes on competitive performance of pollutionintensive industries among transition economies: evidence from panel analysis. Financ Environ Bus Dev 4:155-169.

Tang J (2015) Testing the pollution haven effect: Does the type of FDI matter? Environ Resour Econ 60(4):549578.

Tu Z, Hu T, Shen R (2019) Evaluating public participation impact on environmental protection and ecological efficiency in China: Evidence from PITI disclosure. China Econ Rev 55:111-123.

Vickerman R (2018) Can high-speed rail have a transformative effect on the economy? Transp Policy 62:3137.

Wang H, Liu H (2019) Foreign direct investment, environmental regulation, and environmental pollution: an empirical study based on threshold effects for different Chinese regions. Environ Sci Pollut Res 26(6):5394-5409.

Wang S, Zhou H, Hua G (2020) Is the high-speed rail opening environmentally friendly? Taking the Differencein-Differences test in Jiangsu, China. Complexity 2020(47):147-151. 
Yan X, Jiang P (2018) Effect of the dynamics of human behavior on the competitive spreading of information. Comput Hum Behav 89:1-7.

Yang X, Lin S, Li Y, He M (2019) Can high-speed rail reduce environmental pollution? Evidence from China. J Cleaner Prod 239:118135.

Zhang H, Xiong L, Li L, Zhang S (2018) Political incentives, transformation efficiency and resource-exhausted cities. J Cleaner Prod 196:1418-1428.

Zhang L, Mol AP, He G (2016) Transparency and information disclosure in China's environmental governance. Curr Opin Environ Sustain 18:17-24.

Zheng S, Kahn ME, Sun W, Luo D (2014) Incentives for China's urban mayors to mitigate pollution externalities: The role of the central government and public environmentalism. Region Sci Urban Econ 47:61-71.

Zhou Q, Zeng J (2018) Promotion incentives, GDP manipulation and economic growth in China: How does sub-national officials behave when they have performance pressure? Soc Sci Electron Publish http://dx.doi.org/10.2139/ssrn.3269645. 


\section{Supplementary Files}

This is a list of supplementary files associated with this preprint. Click to download.

- Graphicabstract.docx 